\title{
Effect of sublethal doses of the insecticide imidacloprid on adaptive traits of Drosophila melanogaster: Response to treatment over and after 15 consecutive generations
}

\author{
Thais de França Patarro ${ }^{1}$, Antonio José Manzato², Lílian Madi-Ravazzi ${ }^{1}$, \\ Hermione E. M. de Campos Bicudo ${ }^{1^{*}}$ \\ ${ }^{1}$ Departmento de Biologia, Universidade Estadual Paulista-UNESP, Instituto de Biociências, Letras e Ciências Exatas-IBILCE, São \\ José do Rio Preto, Brazil; "Corresponding Author: bicudo@ibilce.unesp.br \\ ${ }^{2}$ Departmento de Computação, Universidade Estadual Paulista-UNESP, Instituto de Biociências, Letras e Ciências Exatas-IBILCE, \\ São José do Rio Preto, Brazil
}

Received 3 September 2013; revised 8 October 2013; accepted 22 October 2013

Copyright (C) 2013 Thais de França Patarro et al. This is an open access article distributed under the Creative Commons Attribution License, which permits unrestricted use, distribution, and reproduction in any medium, provided the original work is properly cited.

\section{ABSTRACT}

A sublethal dose of Imidacloprid, considered actually as the most widely used insecticide against biting and sucking insects, was administered to Drosophila melanogaster for detecting effects on biological traits. The choice of this species as organism-model potentially opens the possibility to explore more deeply the processes involved in those effects because, among other reasons, there is a large accumulation of biological knowledge on this species and because it propitiates multiple approaches in laboratory and nature. The flies were treated along 15 consecutive generations. F1 parents were randomly taken among virgin flies from the stocks, but the parents of the successive generations were the first 15 couples emerged in the previous one. The number of progeny (productivity) and the duration of the emergence period were analyzed in every generation revealing insecticide toxicity in 12 of the 15 generations. The observation of an increase in the number of progeny over the generations, which occurred in both control and treated experiments (although maintaining higher productivity in the control), suggested an effect of the use of the first 15 emerged couples in successive generations. A comparative analysis of the mortality of the F15 adult flies exposed to imidacloprid by contact, which involved flies from the control, treatment and from the stocks that originated the experiments, reinforced this idea, indicating a genetic interplay of the emergence speed with productivity and adult tolerance to the insecticide, a subject that may be better explored in another study. Toxicity was also observed for the traits longevity, viability during development from egg to adult and oviposition rate. Considering the present intensive use of imidacloprid, the harmful effects observed in these important biological characteristics may be considered able to decrease the adaptive value of $D$. melanogaster populations exposing them at risk of decline.

Keywords: Productivity; Longevity; Emergence Time Period; Egg-Adult Viability; Oviposition; Tolerance

\section{INTRODUCTION}

Imidacloprid $\{1-[(6$-chloro-3-pyridinyl)methyl]- $N$-nitro2 -imidazolidinimine, which is registered in more than a hundred countries in the world, is considered actually the most widely used insecticide for killing sucking and biting insects [1]. Currently, it is intensively used as seed treatment in citrus, cotton, fruits, grapes, potatoes, rice soybeans, sugarcane, tobacco and vegetables [2].

Several studies have provided strong evidence that, in addition to direct mortality, imidacloprid impacts populations through sublethal effects. The exposure to sublethal doses of imidacloprid causes deleterious effects on biological traits of target and non-target organisms. Decrease of the progeny number is one of the most frequent effects in different organisms, but the decreases of 
survival rate and longevity have also been observed in some cases [3,4]. In honeybees (Apis mellifera), probably the more intensively studied non-target organism, imidacloprid is considered one of the causes (or the main cause) of bee populations decline occurring since 1990 [5-8]. In addition, this insecticide has been assigned to a bee malady termed Colony Collapse Disorder (CCD) [9].

Imidacloprid is a neonicotinoid that, similarly to nicotine, acts as an agonist at the postsynaptic acetylcholine receptor (nAChR) [10]. Like other neonicotinoids, imidacloprid causes persistent activation of the receptors leading to hyperexcitation and death [11]. It is effective on contact and via stomach action $[12,8]$. The wide use of the neonicotinoids is due to that they were considered to kill insects by paralyzing nerves but to have low toxicity for other animals. However, data in literature have shown that they affect organisms other than insects. For example, significant adverse effects of this insecticide have been reported in aquatic invertebrates (freshwater and estuarine/marine), being ascribed, at least partially, to its high solubility in water and moderate persistence [13]. In mammals, high doses as well low doses and long exposures were associated with degenerative changes in several organs and other health problems [14].

We used Drosophila melanogaster as organism-model to study how sublethal doses of imidacloprid affect some biological traits. The importance of using Drosophila is that it metabolizes toxic compounds in a way very similar to humans and its biological characteristics favor many possibilities for methodological approaches, in laboratory and nature. Specifically $D$. melanogaster, with a great amount of biological information accumulated in more than a hundred years of studies, may favor the understanding of new observations foreseeing the possibility of a deeper study about the findings. This species has been successfully used as an organism-model for analysis of normal and pathological mechanisms involved with essential human biological processes, including metabolism, development and physiology $[15,16]$.

The treatment in 15 successive generations (nine months of duration) was used to study the impact of the insecticide on a set of biological traits that are very important to preserve the continuity of the species. The results in D. melanogaster confirmed the harmful effects of imidacloprid and raised interesting questions to be answered in future works.

\section{MATERIALS AND METHODS}

\subsection{Strain Origin and Culture in the Laboratory}

The strain used was Drosophila melanogaster from São José do Rio Preto, State of São Paulo, Brazil, collected approximately two years before the beginning of the study, and kept in the Department of Biology of the IBILCE-UNESP. The original mass crosses for preparing the stocks involved more than 20 couples collected in nature. Stocks and experiments were maintained in banana-agar culture medium, at $20^{\circ} \mathrm{C} \pm 1{ }^{\circ} \mathrm{C}$.

\subsection{Experiments}

Imidacloprid (Confidor 700WG, Bayer, 70\% imidacloprid) was administered orally to the flies, being added to the culture medium at $5 \mu \mathrm{g} / \mathrm{mL}$ concentration (value corrected for the percentage contained in the product). This is a sublethal dose, since data unpublished, obtained by L. M. Ravazzi, one of the authors of this paper, for adult flies from the same $D$. melanogaster strain, showed LC50 value $=49.27 \mu \mathrm{g} / \mathrm{ml}$ water.

The present study involved 15 successive generations. In each of them three replicates were prepared for control and three for treatment. Each generation started with the 15 virgin couples first emerged in the previous generation, except the first generation that started with 15 virgin males and females taken randomly from the stocks. Most flies used in F2 to F15 were from the first and second days of emergence, but in some cases, flies from the third day were used to complete the 15 couples.

\subsection{Adaptive Traits Analyzed}

Flies treated with imidacloprid and controls were comparatively analyzed as to their effects on the following traits: 1) productivity (number of progeny); 2) duration of the emergence period (the time elapsed between the emergence of the first and last fly); 3) longevity; 4) oviposition rate; 5) viability from egg to adult stages and 6) mortality of adult flies.

Productivity and duration of the emergence period were evaluated in each of the fifteen generations while the other traits were analyzed in the generation F15, except longevity that was analyzed in F12.

\subsubsection{Productivity and Duration of the Emergence Period}

The number of progeny (productivity) was computed daily in the control $(\mathrm{C})$ and treated $(\mathrm{T})$ replicates, separately by sex, from the beginning to the end of the adults' emergence period, in every generation till the $15^{\text {th }}$.

\subsubsection{Longevity}

Twenty five virgin, recently emerged males and females taken from $\mathrm{F} 12$ generation in $\mathrm{T}$ and $\mathrm{C}$ groups were transferred to tubes containing culture medium with and without the insecticide, respectively. F12 was chosen for this analysis in order to decrease the amount of simultaneous work that would be done in F15. Dead flies were 
computed daily, separately by sex and treatment, till the last one had died. Half-life (the time required for mortality of half of the total number of flies) and mean longevity of the flies were computed.

\subsubsection{Oviposition Rate}

Ten virgin, three days aged males and females from each experimental groups $\mathrm{C}$ and $\mathrm{T}$, and also from the stock that originated the experiments (S), were separately put to cross in tubes containing culture medium (without insecticide for $\mathrm{C}$ and $\mathrm{S}$, and with it for $\mathrm{T}$ flies). The couples were left in the tubes for 8 hours and then the females were individually transferred to empty, clean tubes containing a transparent plastic tea spoon full of agarsugar culture medium (prepared with $0.5 \mathrm{~g}$ agar-agar dissolved in $100 \mathrm{~mL}$ of hot water and addition of $2.5 \mathrm{~g}$ sugar). Twenty-two hours latter, the spoons were removed for counting the eggs (in a stereomicroscope) and a second set of spoons was included in the same vials. The eggs in this second set of spoons were counted again after $22 \mathrm{~h}$, totalizing $44 \mathrm{~h}$ observation.

\subsubsection{Viability Egg-Adult}

The eggs obtained in the study of the oviposition rate were used in the analysis of viability egg-adult. After being computed for oviposition rate, the eggs from T, C and $\mathrm{S}$ flies were put for development in the respective culture medium and the percentage of adults obtained in relation to the initial number of eggs gave the viability egg-adult. Males and females were computed separately.

\subsubsection{Mortality of Adult Flies Exposed to Imidacloprid by Contact}

This experiment was done in order to detect possible changes in the degree of tolerance of the adults after 15 generations of treatment. Adult flies from $\mathrm{C}$ and $\mathrm{T}$ groups taken in F15, and $\mathrm{S}$ flies were put in contact with the insecticide at $10 \mathrm{mg} / \mathrm{mL}$ water concentration) imbibed in pieces of filter paper introduced in the vials. This analysis intended also to detect the existence of interference of the method used (selection of the first 15 couples), in the results. Ninety couples, three days old (virgin males and females), from each experimental group, were put in contact with the imidacloprid. Strips of filter paper were impregnated with the aqueous solution of the insecticide, put to air dry and placed into the tubes $(9.0 \mathrm{~cm} \times 6.5 \mathrm{~cm})$, covering their interior. Females and males were placed separately in these tubes. The count of dead flies was done at 24 and 48 hours after exposing the flies to the impregnated paper. For making sure that the flies didn't die due to desiccation or hunger, a piece of cotton imbibed in aqueous solution of glucose $(0.8 \%)$ was fixed in the upper part of the tube.

\subsection{Statistical Analysis}

Statistical analysis of the data involved exploratory analysis, Student's t-test, non-parametric test of KruskalWallis, $\chi^{2}$ for comparison of several proportions, Tukey test for multiple comparisons of proportions two by two (involving the Tukey's angular transformation). and the $\mathrm{Z}$ test with normal approximation. The statistical methods used were based on [17] and [18]. The software was the Minitab Release Package 14.

\section{RESULTS}

\subsection{Characteristics Analyzed in the $\mathbf{1 5}$ Generations}

\subsubsection{Productivity}

The descriptive statistics (Table 1) shows, for each generation, the data on the mean number of progeny and standard error, separately for males and females, in C and $\mathrm{T}$ experiments. The total number of progeny produced in both experiments was 16,620 flies.

The smallest productivity was obtained in the first generation. The mean values for $\mathrm{C}$ and $\mathrm{T}$ replicates of this generation were 98.3 and 84.7, respectively, while the mean for F2 to F15 was 219.21 for C and 163.46 for $\mathrm{T}$. The mean of the means of the progeny in the 15 generations was: for males, $\mathrm{C}=104.23$ and $\mathrm{T}=79.93$; for females, $\mathrm{C}=106.44$ and $\mathrm{T}=78.23$; and for males plus females, $\mathrm{C}=211.15$ and $\mathrm{T}=158.21$.

Student's t-test for comparison between $\mathrm{C}$ and $\mathrm{T}$ experiments relative to the mean productivity of males, females and their sum, in each generation (Table 2), showed that the differences between $\mathrm{C}$ and $\mathrm{T}$ were significant for males in the generations $\mathrm{F} 4(\mathrm{t}=3.37, \mathrm{P}=$ $0.003), \mathrm{F} 9(\mathrm{t}=3.05, \mathrm{P}=0.039$ and $\mathrm{F} 12 \mathrm{~T}=17.17, \mathrm{P}=$ $0.00^{+}$[P value close to zero]). For females, the significant differences were detected in F6 $(\mathrm{t}=3.14, \mathrm{P}=0.003)$ and $\mathrm{F} 12(\mathrm{t}=5.23, \mathrm{P}=0.001)$, and for the mean total progeny (males plus females), in F1 $(\mathrm{t}=3.04, \mathrm{P}=0.039, \mathrm{~F} 4(\mathrm{t}=$ $2.75, \mathrm{P}=0.048), \mathrm{F} 6(\mathrm{t}=2.80, \mathrm{P}=0.049), \mathrm{F} 9(\mathrm{t}=2.82, \mathrm{P}$ $=0.047)$ and $F 12(t=9.31, P=0.000)$. In every case of significant difference, values in $\mathrm{C}$ were greater than in $\mathrm{T}$. However, in the light of the numbers, male progeny was greater in $\mathrm{C}$ than in $\mathrm{T}$ in 12 of the 15 generations, female progeny, in 10, and males plus females in 12 .

Boxplot of data (Figure 1) showed the wide variation of the progeny number among replicates, mainly for $\mathrm{C}$ group. To better visualize the difference between $\mathrm{C}$ and $\mathrm{T}$ over generations the results were submitted to the statistical method of smoothing $4253 \mathrm{H}$ (Figure 2). With this method, significant differences on progeny number were found for males in F3 to F12, for females in F5 and F9, and for males plus females, in F6 to F11. Except in F11, the productivity was lower in $\mathrm{T}$ experi- 
Table 1. Mean and standard error of data on productivity (number of progeny) separately for males, females and males plus females (Total) in the control (C) and imidacloprid treated (T) experiments of the 15 generations.

\begin{tabular}{|c|c|c|c|c|c|c|c|c|c|c|}
\hline \multirow{2}{*}{ Generations } & & \multicolumn{3}{|c|}{ Males } & \multicolumn{3}{|c|}{ Females } & \multicolumn{3}{|c|}{ Total } \\
\hline & & Mean & \pm & s.e. & Mean & \pm & s.e. & Mean & \pm & s.e. \\
\hline \multirow{2}{*}{$\mathrm{F} 1$} & $\mathrm{C}$ & 48.0 & \pm & 2.6 & 43.7 & \pm & 4.7 & 98.3 & \pm & 0.3 \\
\hline & $\mathrm{T}$ & 41.7 & \pm & 4.2 & 43.0 & \pm & 3.1 & 84.7 & \pm & 4.5 \\
\hline \multirow{2}{*}{$\mathrm{F} 2$} & $\mathrm{C}$ & 125.3 & \pm & 19.9 & 115.3 & \pm & 15.7 & 240.7 & \pm & 35.4 \\
\hline & $\mathrm{T}$ & 84.0 & \pm & 10.1 & 78.3 & \pm & 3.2 & 162.3 & \pm & 12.3 \\
\hline \multirow{2}{*}{ F3 } & $\mathrm{C}$ & 65.3 & \pm & 2.0 & 58.3 & \pm & 11.6 & 123.7 & \pm & 13.2 \\
\hline & $\mathrm{T}$ & 62.3 & \pm & 8.8 & 64.3 & \pm & 6.4 & 126.7 & \pm & 14.2 \\
\hline \multirow{2}{*}{ F4 } & $\mathrm{C}$ & 92.3 & \pm & 8.6 & 101.3 & \pm & 14.0 & 194.0 & \pm & 22.9 \\
\hline & $\mathrm{T}$ & 62.0 & \pm & 2.5 & 69.0 & \pm & 1.7 & 131.0 & \pm & 1.2 \\
\hline \multirow{2}{*}{ F5 } & $\mathrm{C}$ & 89.0 & \pm & 7.0 & 86.7 & \pm & 6.4 & 175.7 & \pm & 13.2 \\
\hline & $\mathrm{T}$ & 76.0 & \pm & 1.5 & 78.0 & \pm & 14.4 & 154.0 & \pm & 15.8 \\
\hline \multirow{2}{*}{ F6 } & $\mathrm{C}$ & 136.3 & \pm & 23.2 & 136.7 & \pm & 20.2 & 273.0 & \pm & 42.8 \\
\hline & $\mathrm{T}$ & 80.0 & \pm & 7.2 & 67.3 & \pm & 9.0 & 147.3 & \pm & 13.2 \\
\hline \multirow{2}{*}{ F7 } & $\mathrm{C}$ & 75.0 & \pm & 2.3 & 84.0 & \pm & 8.1 & 159.0 & \pm & 8.1 \\
\hline & $\mathrm{T}$ & 67.3 & \pm & 7.3 & 64.3 & \pm & 4.9 & 131.7 & \pm & 11.9 \\
\hline \multirow{2}{*}{ F8 } & $\mathrm{C}$ & 122.0 & \pm & 13.8 & 110.7 & \pm & 11.9 & 232.7 & \pm & 25.7 \\
\hline & $\mathrm{T}$ & 89.0 & \pm & 4.7 & 95.7 & \pm & 10.5 & 184.7 & \pm & 15.0 \\
\hline \multirow{2}{*}{ F9 } & $\mathrm{C}$ & 124.0 & \pm & 11.4 & 126.3 & \pm & 4.1 & 250.3 & \pm & 13.2 \\
\hline & $\mathrm{T}$ & 85.0 & \pm & 5.9 & 86.7 & \pm & 19.7 & 171.7 & \pm & 24.6 \\
\hline \multirow{2}{*}{ F10 } & $\mathrm{C}$ & 102.3 & \pm & 17.6 & 102.0 & \pm & 17.1 & 204.3 & \pm & 33.3 \\
\hline & $\mathrm{T}$ & 59.3 & \pm & 12.4 & 53.3 & \pm & 7.8 & 112.7 & \pm & 19.3 \\
\hline \multirow{2}{*}{ F11 } & $\mathrm{C}$ & 66.0 & \pm & 2.1 & 60.3 & \pm & 2.8 & 126.3 & \pm & 1.2 \\
\hline & $\mathrm{T}$ & 86.7 & \pm & 11.9 & 87.3 & \pm & 13.0 & 174.0 & \pm & 22.3 \\
\hline \multirow{2}{*}{ F12 } & $\mathrm{C}$ & 195.0 & \pm & 1.5 & 194.0 & \pm & 13.5 & 389.0 & \pm & 12.6 \\
\hline & $\mathrm{T}$ & 110.7 & \pm & 4.7 & 109.0 & \pm & 9.0 & 219.7 & \pm & 13.1 \\
\hline \multirow{2}{*}{ F13 } & $\mathrm{C}$ & 154.7 & \pm & 8.5 & 169.3 & \pm & 18.2 & 324.0 & \pm & 26.6 \\
\hline & $\mathrm{T}$ & 119.3 & \pm & 16.3 & 119.3 & \pm & 35.4 & 238.7 & \pm & 50.4 \\
\hline \multirow{2}{*}{ F14 } & $\mathrm{C}$ & 59.3 & \pm & 10.4 & 60.7 & \pm & 17.4 & 120.0 & \pm & 26.2 \\
\hline & $\mathrm{T}$ & 78.7 & \pm & 7.4 & 71.3 & \pm & 15.2 & 150.3 & \pm & 21.1 \\
\hline \multirow{2}{*}{ F15 } & $\mathrm{C}$ & 109.0 & \pm & 16.5 & 147.3 & \pm & 28.9 & 256.3 & \pm & 44.5 \\
\hline & $\mathrm{T}$ & 97.0 & \pm & 7.5 & 86.7 & \pm & 3.3 & 183.7 & \pm & 10.0 \\
\hline \multirow[b]{2}{*}{ Mean } & $\mathrm{C}$ & \multicolumn{3}{|c|}{104.23} & \multicolumn{3}{|c|}{106.44} & \multicolumn{3}{|c|}{211.15} \\
\hline & $T$ & \multicolumn{3}{|c|}{79.93} & & \multicolumn{3}{|c|}{211.15} \\
\hline
\end{tabular}


Table 2. Differences of means on productivity (number of progeny) between control (C) and imidacloprid treated (T) experiments, separately for males, females and males plus females (Total), using normal data.

\begin{tabular}{|c|c|c|c|c|c|c|c|c|c|}
\hline \multicolumn{10}{|c|}{ Difference of Means } \\
\hline \multirow[b]{2}{*}{ Generation } & \multicolumn{3}{|c|}{ Males } & \multicolumn{3}{|c|}{ Females } & \multicolumn{3}{|c|}{ Total } \\
\hline & $\mathrm{C}-\mathrm{T}$ & $\mathrm{t}$ & $\mathrm{P}$ & $\mathrm{C}-\mathrm{T}$ & $\mathrm{t}$ & $\mathrm{P}$ & $\mathrm{C}-\mathrm{T}$ & $\mathrm{t}$ & $\mathrm{P}$ \\
\hline F1 & 6.3 & 1.28 & 0.250 & 0.7 & 0.12 & 0.925 & 13.7 & 3.04 & 0.039 \\
\hline F2 & 41.3 & 1.85 & 0.168 & 37.0 & 2.31 & 0.055 & 78.3 & 2.09 & 0.100 \\
\hline F3 & 3.0 & 0.33 & 0.678 & -6.0 & -0.45 & 0.756 & -3.0 & -0.15 & 0.852 \\
\hline F4 & 30.3 & 3.37 & 0.003 & 32.3 & 2.30 & 0.057 & 63.0 & 2.75 & 0.048 \\
\hline F5 & 13.0 & 1.81 & 0.182 & 8.7 & 0.55 & 0.659 & 21.7 & 1.05 & 0.389 \\
\hline F6 & 56.3 & 2.32 & 0.058 & 69.3 & 3.14 & 0.003 & 125.7 & 2.80 & 0.049 \\
\hline F7 & 7.7 & 1.00 & 0.392 & 19.7 & 2.08 & 0.102 & 27.3 & 1.90 & 0.112 \\
\hline F8 & 33.0 & 2.26 & 0.058 & 15.0 & 0.94 & 0.400 & 48.0 & 1.61 & 0.123 \\
\hline F9 & 39.0 & 3.05 & 0.039 & 39.7 & 1.97 & 0.115 & 78.7 & 2.82 & 0.047 \\
\hline F10 & 43.0 & 2.00 & 0.096 & 48.7 & 2.59 & 0.056 & 91.7 & 2.38 & 0.057 \\
\hline F11 & -20.7 & -1.72 & 0.150 & -27.0 & -2.03 & 0.123 & -47.7 & -2.13 & 0.100 \\
\hline F12 & 84.3 & 17.17 & $0.00^{+}$ & 85.0 & 5.23 & 0.001 & 169.3 & 9.31 & $0.00^{+}$ \\
\hline F13 & 35.3 & 1.93 & 0.183 & 50.0 & 1.26 & 0.278 & 85.3 & 1.50 & 0.221 \\
\hline F14 & -19.3 & -1.52 & 0.200 & -10.7 & -0.46 & 0.723 & -30.3 & -0.90 & 0.398 \\
\hline F15 & 12.0 & 0.66 & 0.552 & 60.7 & 2.08 & 0.100 & 72.7 & 1.59 & 0.223 \\
\hline
\end{tabular}

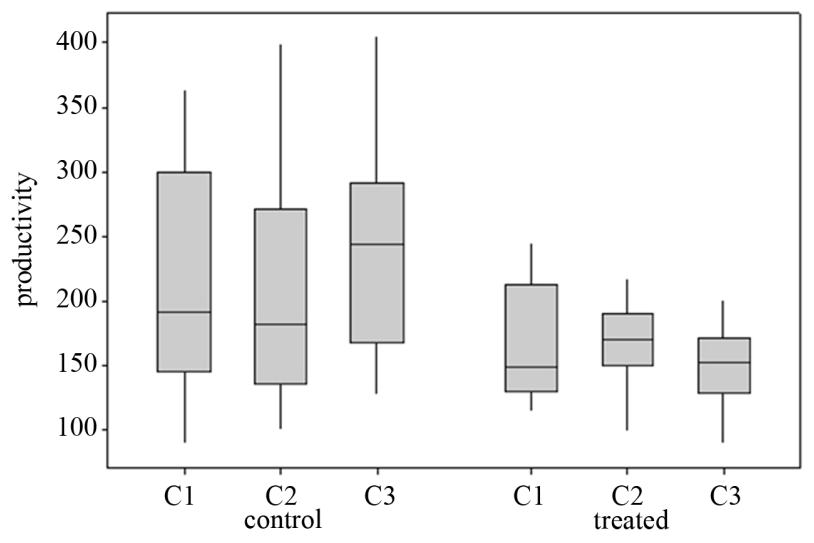

Figure 1. Boxplot for productivity (total number of progeny) of the replicates in the experiments control $(\mathrm{C} 1, \mathrm{C} 2$ and $\mathrm{C} 3)$ and imidacloprid treated (T1, T2 and T3).

ments. The smoothing data also allowed visualizing more clearly the increase in the number of offspring that occurred in $\mathrm{C}$ and $\mathrm{T}$, over generations (Table 3 ).

\subsubsection{Duration of the Emergence Period}

The time, in days, elapsed between the emergence of the first fly and the last one was also evaluated in each replicate of the fifteen generations of $\mathrm{C}$ and $\mathrm{T}$ experiments (Figure 3). Seen in the light of the numbers, nine of the fifteen generations showed mean emergence duration of $\mathrm{C}$ replicates greater than that from T. Student's t-test showed significant difference between them only in $\mathrm{F} 6(\mathrm{t}=6.01 ; \mathrm{P}=0.027)$ and $\mathrm{F} 8(\mathrm{t}=3.77 ; \mathrm{P}=0.033)$.

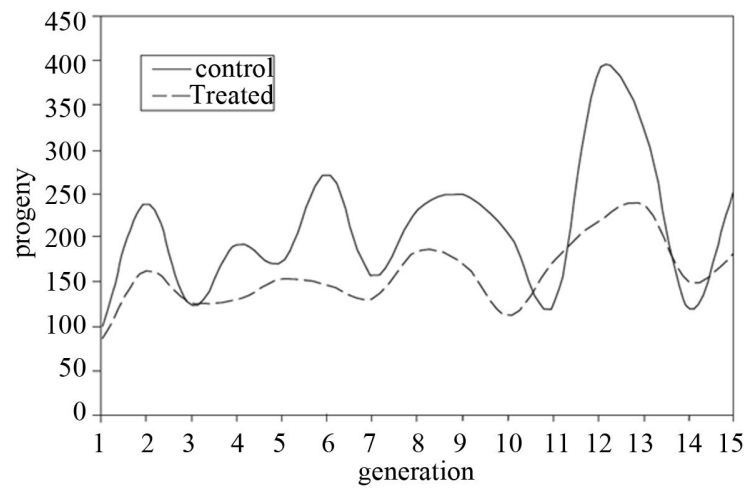

(a)

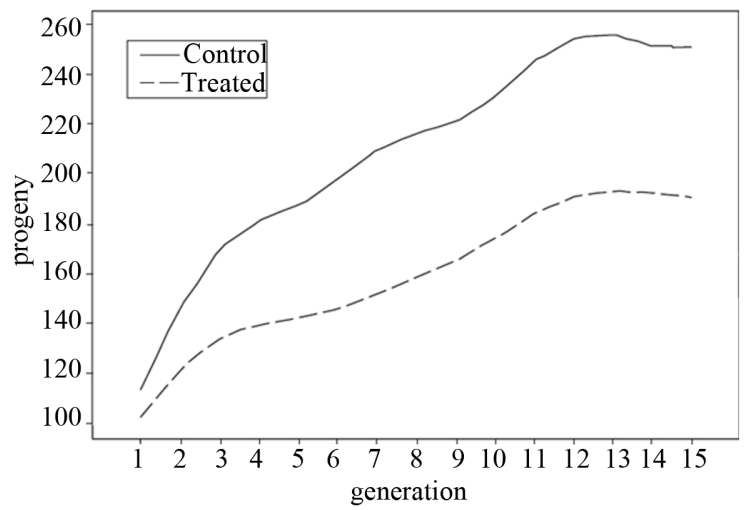

(b)

Figure 2. Graphs for mean productivity in the groups control and imidacloprid treated, in the generations F1 to F15. (a): Normal data; (b): Smoothed data. 
Table 3. Differences of means on productivity (number of progeny) between control (C) and imidacloprid treated (T) experiments, separately for males, females and males plus females (Total), using smoothed data.

\begin{tabular}{|c|c|c|c|c|c|c|c|c|c|}
\hline \multirow[b]{2}{*}{ Generation } & \multicolumn{3}{|c|}{ Males } & \multicolumn{3}{|c|}{ Females } & \multicolumn{3}{|c|}{ Total } \\
\hline & C-T & $\mathrm{t}$ & $\mathrm{P}$ & C-T & $\mathrm{t}$ & $\mathrm{P}$ & C-T & $\mathrm{t}$ & $\mathrm{P}$ \\
\hline $\mathrm{F} 1$ & 7.4 & 1.2 & 0.18 & -3.6 & -1.07 & 0.191 & 11.5 & 1.12 & 0.191 \\
\hline $\mathrm{F} 2$ & 13.8 & 2.3 & 0.05 & 10.9 & 1.55 & 0.13 & 26.2 & 1.84 & 0.07 \\
\hline F3 & 17.8 & 2.5 & 0.04 & 20.1 & 2.00 & 0.055 & 36.6 & 2.04 & 0.085 \\
\hline F4 & 19.5 & 2.4 & 0.02 & 24.0 & 2.26 & 0.052 & 42.2 & 2.16 & 0.058 \\
\hline F5 & 21.6 & 2.4 & 0.02 & 25.9 & 2.49 & 0.03 & 45.7 & 2.26 & 0.056 \\
\hline F6 & 26.2 & 2.6 & 0.03 & 28.0 & 2.73 & 0.028 & 51.9 & 2.53 & 0.041 \\
\hline F7 & 30.3 & 2.8 & 0.03 & 29.0 & 3.2 & 0.024 & 57.4 & 2.92 & 0.027 \\
\hline F8 & 30.7 & 2.9 & 0.03 & 28.9 & 3.54 & 0.012 & 58 & 3.07 & 0.025 \\
\hline F9 & 28.6 & 2.7 & 0.03 & 28.2 & 3.00 & 0.026 & 56.2 & 2.96 & 0.031 \\
\hline F10 & 26.6 & 2.7 & 0.03 & 29.6 & 2.35 & 0.051 & 57.4 & 2.74 & 0.032 \\
\hline F11 & 25.7 & 2.7 & 0.03 & 34.1 & 2.12 & 0.061 & 61.3 & 2.44 & 0.034 \\
\hline F12 & 24.6 & 2.6 & 0.03 & 38.2 & 2.18 & 0.06 & 63.5 & 2.31 & 0.057 \\
\hline F13 & 21.1 & 2.2 & 0.06 & 41.0 & 2.36 & 0.062 & 62.4 & 2.16 & 0.059 \\
\hline F14 & 15.6 & 1.3 & 0.11 & 42.6 & 2.46 & 0.046 & 58.9 & 1.79 & 0.085 \\
\hline F15 & 12.6 & 0.7 & 0.18 & 43.0 & 2.28 & 0.055 & 60.1 & 1.52 & 0.089 \\
\hline
\end{tabular}

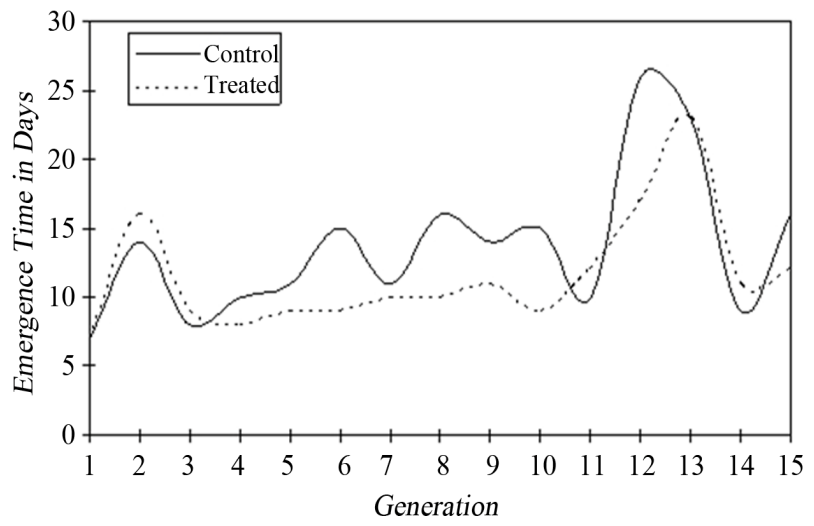

Figure 3. Means of emergence time duration of progeny (in days) from the control and imidacloprid treated experiments, in each of the 15 generations.

However, among the other seven non-significant generations with mean duration of emergence period greater in $\mathrm{C}$, the difference from $\mathrm{T}$ varied from two to six days. The mean of the replicate means for all generations was 13.66 days for $\mathrm{C}$ and 11.54 days for $\mathrm{T}$ (Tables 4 and 5).

Due to the similarity of profiles in the graphs of number of progeny and emergence time duration, the coefficient of correlation was calculated for each replicate using Pearson's coefficient of linear correlation and significance test for $\mathrm{P}=0.00^{+}$. Except in the replicate number 3 of $\mathrm{T}$, the two characteristics showed high correlation: control $\mathrm{P}=0.95$; treated $\mathrm{P}=0.85$ (Figure 4).
Table 4. Duration (in days) of the emergence period computed from the first to the last fly emerged in the replicates from experiments control $(\mathrm{C} 1, \mathrm{C} 2, \mathrm{C} 3)$ and imidacloprid treated $(\mathrm{T} 1$, $\mathrm{T} 2, \mathrm{~T} 3)$, in the 15 generations.

\begin{tabular}{ccccccccc}
\hline \multicolumn{7}{c}{ Emergence Time (days) } \\
\hline Generation & C1 & C2 & C3 & Mean & T1 & T2 & T3 & Mean \\
\hline F1 & 7 & 7 & 8 & 7.33 & 5 & 7 & 8 & 6.67 \\
F2 & 16 & 9 & 16 & 13.67 & 16 & 15 & 16 & 15.67 \\
F3 & 8 & 7 & 9 & 8.00 & 6 & 11 & 11 & 9.33 \\
F4 & 10 & 8 & 12 & 10.00 & 8 & 8 & 9 & 8.33 \\
F5 & 11 & 8 & 14 & 11.00 & 8 & 13 & 7 & 9.33 \\
F6 & 16 & 13 & 16 & 15.00 & 9 & 9 & 9 & 9.00 \\
F7 & 14 & 11 & 9 & 11.33 & 12 & 9 & 9 & 10.00 \\
F8 & 17 & 13 & 17 & 15.67 & 11 & 10 & 8 & 9.67 \\
F9 & 17 & 13 & 12 & 14.00 & 15 & 10 & 9 & 11.33 \\
F10 & 19 & 10 & 15 & 14.67 & 10 & 9 & 8 & 9.00 \\
F11 & 11 & 12 & 8 & 10.33 & 10 & 12 & 13 & 11.67 \\
F12 & 28 & 25 & 24 & 25.67 & 21 & 19 & 12 & 17.33 \\
F13 & 26 & 19 & 23 & 22.67 & 31 & 22 & 15 & 22.67 \\
F14 & 6 & 11 & 11 & 9.33 & 13 & 10 & 10 & 11.00 \\
F15 & 25 & 10 & 12 & 15.67 & 13 & 14 & 8 & 11.67 \\
\hline
\end{tabular}


Table 5. Student's t-test for comparison on duration of emergence time of progeny from control and imidacloprid treated experiments, in the 15 generations.

\begin{tabular}{ccc}
\hline Generation & $\mathrm{t}$ & $\mathrm{P}$ \\
\hline F1 & 0.71 & 0.549 \\
F2 & 0.85 & 0.485 \\
F3 & 0.76 & 0.529 \\
F4 & 1.39 & 0.299 \\
F5 & 0.66 & 0.557 \\
F6 & 6.01 & $0.027^{*}$ \\
F7 & 0.76 & 0.505 \\
F8 & 3.77 & $0.033^{*}$ \\
F9 & 1.11 & 0.347 \\
F10 & 2.13 & 0.167 \\
F11 & 0.89 & 0.437 \\
F12 & 2.80 & 0.108 \\
F13 & 0.00 & 0.999 \\
F14 & 0.86 & 0.453 \\
F15 & 0.79 & 0.511 \\
\hline
\end{tabular}

${ }^{*}=$ significant values.

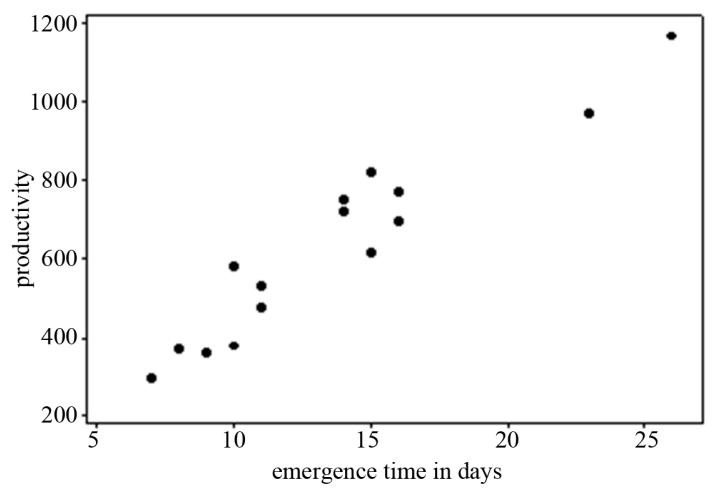

(a)

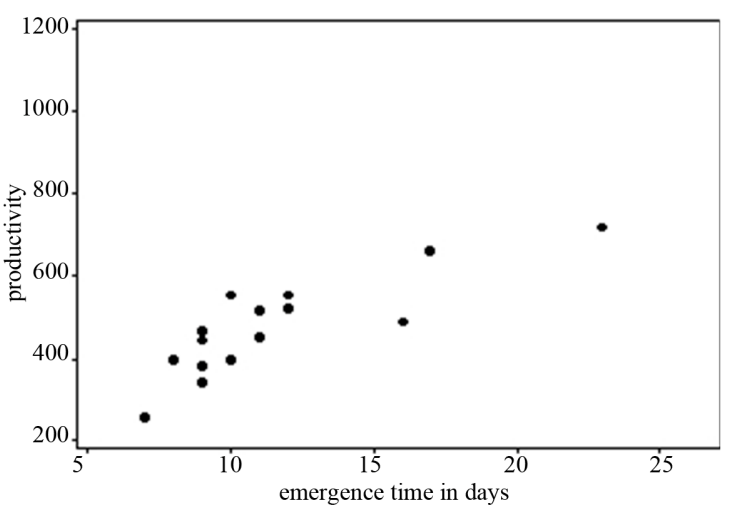

(b)

Figure 4. Dispersion graphs between total productivity and mean emergence time for control (a) and imidacloprid treated (b) experiments (Pearson's linear correlation $r=0.95$ and $r=0.85$, respectively).

\subsection{Characteristics Analyzed in a Single Generation}

\subsubsection{Longevity}

The time elapsed between the emergence and the death of the adult flies was studied for virgin males and females from F12, in $\mathrm{C}$ and $\mathrm{T}$ groups. Longevity graphs (Figures 5 and 6), showed that, in $\mathrm{C}$ experiments, half life was approximately 58 days for females and 57 days for males while, in $\mathrm{T}$, they were about 50 and 48 days, respectively Mean longevity values for C were 54.32 days for females and 56.84 days for males while for $\mathrm{T}$, they were 50.52 and 48.92 , respectively. Thus, in the $\mathrm{T}$ experiments, the mean longevity was reduced in 7.92 days for males and 3.80 days for females.

\subsubsection{Oviposition Rate}

Egg numbers were counted at the first and second $22 \mathrm{~h}$ periods after flies from groups $\mathrm{C}, \mathrm{T}$ and from $\mathrm{S}$ (stock) were put in contact with the specific culture medium (Figure 7). Due to the variability of the standard error,

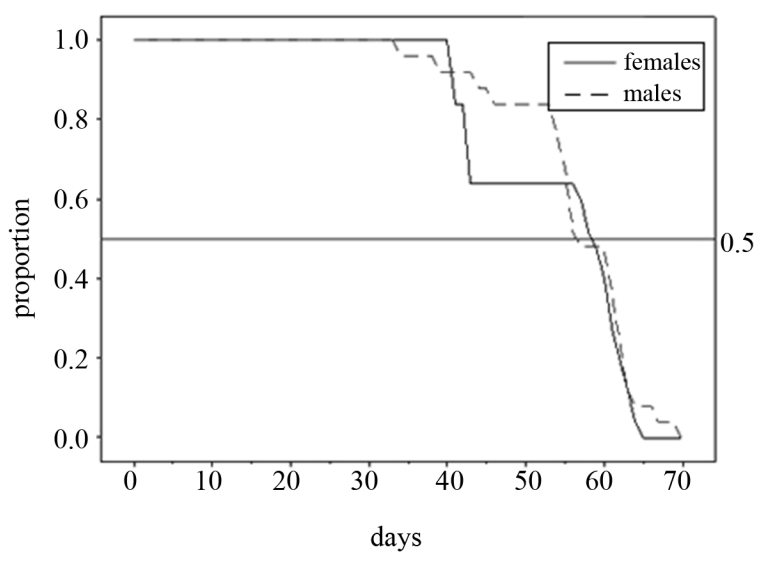

(a)

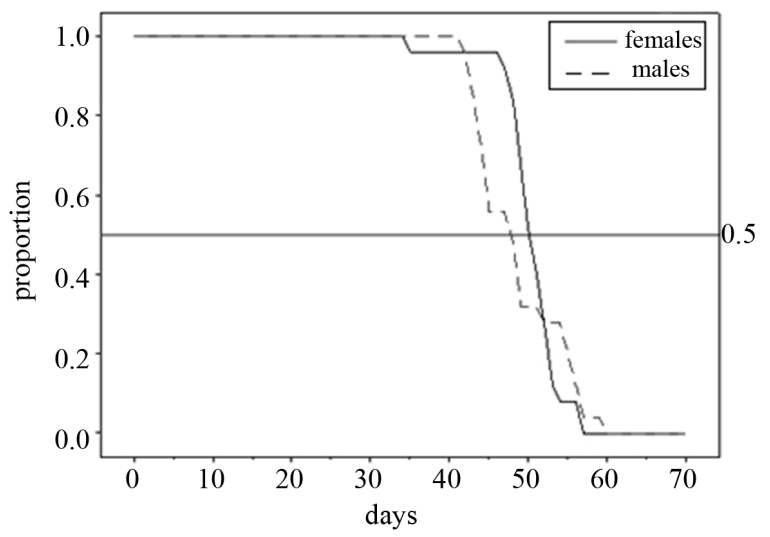

(b)

Figure 5. Graphs for comparison of longevity between males and females from F12 generation, in the control (a) and imidacloprid treated (b) groups. Horizontal line at 0.5 proportion indicates half-life value. 


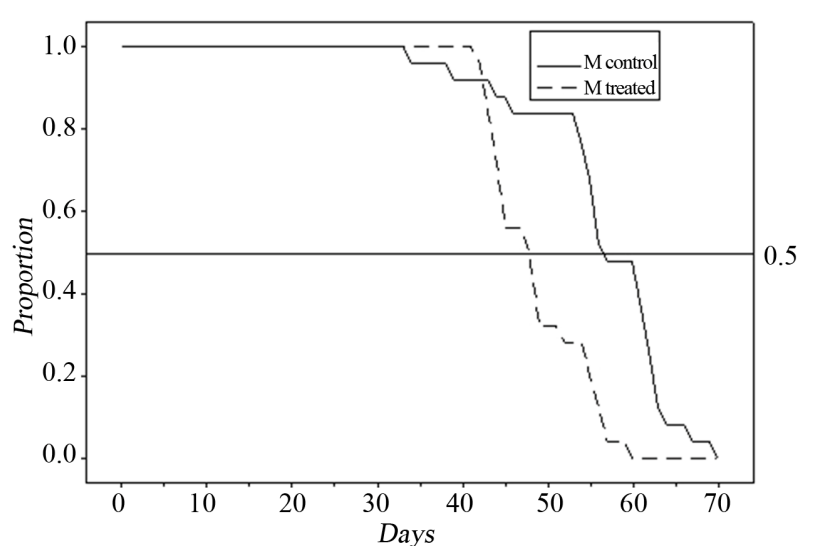

(a)

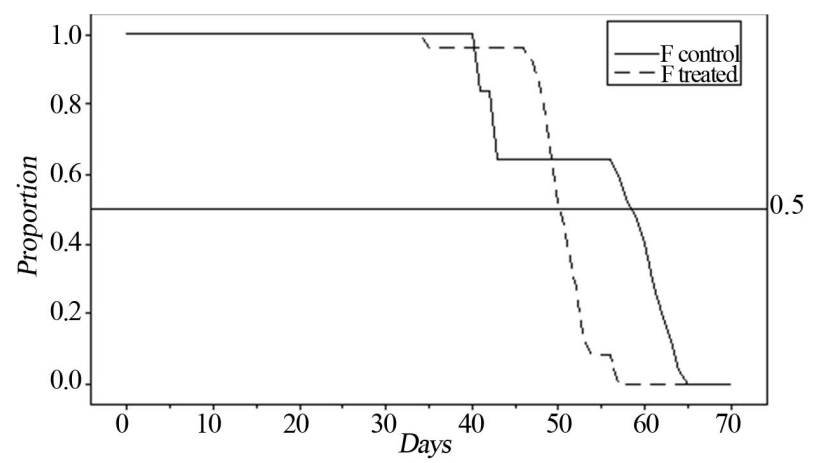

(b)

Figure 6. Graphs for comparison of longevity between control and imidacloprid treated flies, from the F12 generation, for males (a) and females (b). Horizontal line at 0.5 proportion indicates half-life value.

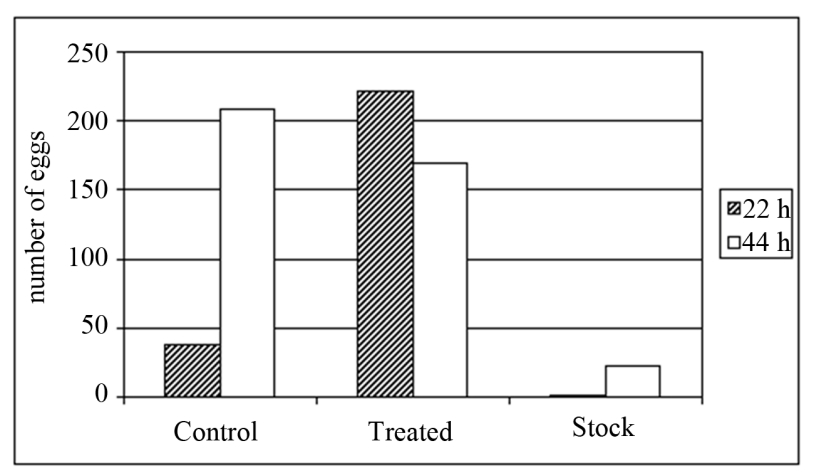

Figure 7. Distribution graph of the oviposition rate, computed at 22 and $44 \mathrm{~h}$ after the beginning of the experiment, for flies from the control (C), the imidacloprid treated experiment $(\mathrm{T})$ and the stock $(\mathrm{S})$.

the non-parametric test Kruskal-Wallis for comparison of the experimental groups and pairwise comparisons between groups were used in the analyses.

Kuskal-Wallis statistics $(\mathrm{H})$ and $\mathrm{P}$ values for compareson among groups, at 22 and $44 \mathrm{~h}$ showed significant differences in both counts: at $22 \mathrm{~h}(\mathrm{H}=18.94 ; \mathrm{P}=0.000)$ and at $44 \mathrm{~h}(\mathrm{H}=13.68, \mathrm{P}=0.001)$. Pairwise comparisons showed that the oviposition proportion at $22 \mathrm{~h}$ was higher for flies from $\mathrm{T}$ than from $\mathrm{C}(\mathrm{q}=3.376)$, higher for flies from $\mathrm{T}$ than from $\mathrm{S}(\mathrm{q}=5.855)$ and did not differ between $\mathrm{C}$ and $\mathrm{S}(\mathrm{q}=2.478)$. Thus, at $22 \mathrm{~h}, \mathrm{~T}>\mathrm{C}=\mathrm{S}$. At $44 \mathrm{~h}$, the oviposition proportion was higher in $\mathrm{C}$ than in $\mathrm{S}(\mathrm{q}=4.993)$ and also higher in $\mathrm{T}$ than in $\mathrm{S}(\mathrm{q}=3.771)$ but it did not differ between $\mathrm{C}$ and $\mathrm{T}(\mathrm{q}=1.221)$. Thus, at $44 \mathrm{~h}, \mathrm{~T}=\mathrm{C}>\mathrm{S}$. In every case, critic q value was 3.134. In the total time of observation, $\mathrm{C}$ flies laid 246 eggs, $\mathrm{T}$ flies 381 and $\mathrm{S}$ flies 23. The differences in the oviposition rate between the first and second $22 \mathrm{~h}$ periods, in each group, was evaluated using Student's t-test for paired data and showed significant differences only for $\mathrm{C}$, being the oviposition rate at the second $22 \mathrm{~h}$ period higher than that at the first $22 \mathrm{~h}(\mathrm{t}=4.24 ; \mathrm{P}=0.002)$ (Table 6$)$.

\subsubsection{Viability Egg-Adult}

The viability egg-adult was analyzed for $\mathrm{C}, \mathrm{T}$ and $\mathrm{S}$ flies, using the eggs collected in the tests for oviposition rate (Table 7). The comparisons between groups relative to the proportion of males, females and males plus females obtained from egg samples showed significant differences for females $\left(\chi^{2}=22.26, \mathrm{P}=0.00^{+}\right)$, for males $\left(\chi^{2}=10.42, \mathrm{P}=0.027\right)$ and for total progeny $\left(\chi^{2}=30.95\right.$, $\left.\mathrm{P}=0.00^{+}\right) \cdot \chi^{2}$ analysis was also used for pairwise comparisons of groups as to the difference of proportion of males, females and total of flies obtained from the eggs. The result was the same in every comparison, that is, viability egg-adult in $\mathrm{T}$ was smaller than in $\mathrm{C}$ and $\mathrm{S}$, which did not differ from each other. Thus, $\mathrm{T}<\mathrm{C}=\mathrm{S}$. (for females: $\mathrm{T} \times \mathrm{S}, \mathrm{q}=4.559, \mathrm{~T} \times \mathrm{C}, \mathrm{q}=5.583$ and $\mathrm{C} \times$ $\mathrm{S}, \mathrm{q}=1.705$; for males and for males plus females $\mathrm{T} \times \mathrm{S}$, $\mathrm{q}=4.95, \mathrm{~T} \times \mathrm{C}, \mathrm{q}=4.26, \mathrm{C} \times \mathrm{S}, \mathrm{q}=1.95$. In every case, critical q was 3.682 .

$\mathrm{Z}$ statistics for comparison of the mortality rate between adult females and males in each group (C, T and $\mathrm{S}$ ) showed significant differences in $\mathrm{C}$, in the second $24 \mathrm{~h}$ $(\mathrm{Z}=2.51, \mathrm{P}=0.012)$ and in the total $48 \mathrm{~h}$ exposure $(\mathrm{Z}=$ $2.32, \mathrm{P}=0.020$ ), and in $\mathrm{T}$ (in the $48 \mathrm{~h}, \mathrm{Z}=2.72, \mathrm{P}=$ $0.007)$. In both groups, mortality rate of males was greater than that of females. However, considering the numbers, the male mortality was higher than that of females in the three exposition times of $S$ flies $\left(1^{\text {st }} 24,2^{\text {nd }}\right.$ 24 and total $48 \mathrm{~h}$ ) and also in the $2^{\text {nd }} 24 \mathrm{~h}$ exposure of T.

\subsubsection{Mortality of Adults}

Data on mortality were obtained for adult flies from C, $\mathrm{T}$ and $\mathrm{S}$ exposed to imidacloprid and evaluated after the first and second $24 \mathrm{~h}$ exposition, separately for females, males and females plus males (Table 8). Comparison among groups could not be done for females and for males at the first $24 \mathrm{~h}$ due to the low frequency of dead flies (less than five). For females, in the second $24 \mathrm{~h}$ and 
Table 6. Difference of oviposition values in comparisons of the control (C), imidacloprid treated (T) and flies from the stock (S) as to the number of eggs laid at 22 and $44 \mathrm{~h}$, including residual squares.

\begin{tabular}{cccccccccccc}
\hline \multicolumn{1}{c}{$22 \mathrm{~h}$} & \multicolumn{5}{c}{$44 \mathrm{~h}$} \\
\hline Comparisons & $\mathrm{R}_{\mathrm{i}}-\mathrm{R}_{\mathrm{j}}$ & $\mathrm{SE}$ & $\mathrm{q}$ & $\mathrm{q}_{\text {critical }}$ & Conclusion & $\mathrm{R}_{\mathrm{i}}-\mathrm{R}_{\mathrm{j}}$ & $\mathrm{SE}$ & $\mathrm{q}$ & $\mathrm{q}_{\text {critical }}$ & Conclusion \\
$\mathrm{T} \times \mathrm{C}$ & 94 & 27.84 & 3.376 & 3.134 & $\mathrm{~T}>\mathrm{C}$ & 34 & 27.84 & 1.221 & 3.134 & $\mathrm{C}=\mathrm{T}$ \\
$\mathrm{T} \times \mathrm{S}$ & 163 & 27.84 & 5.855 & 3.134 & $\mathrm{~T}>\mathrm{S}$ & 105 & 27.84 & 3.771 & 3.134 & $\mathrm{~T}>\mathrm{S}$ \\
$\mathrm{C} \times \mathrm{S}$ & 69 & 27.84 & 2.478 & 3.134 & $\mathrm{C}=\mathrm{S}$ & 139 & 27.84 & 4.993 & 3.134 & $\mathrm{C}>\mathrm{S}$ \\
\hline
\end{tabular}

Table 7. Multiple pairwise comparisons for data on egg to adult viability of flies from the control (C), imidacloprid treated (T) and stock (S).

\begin{tabular}{|c|c|c|c|c|}
\hline \multirow{2}{*}{ Sex } & \multicolumn{3}{|c|}{ Experiments } & \multirow{2}{*}{ Conclusions } \\
\hline & $\mathrm{T}$ & $\mathrm{C}$ & S & \\
\hline \multicolumn{5}{|l|}{ Females } \\
\hline Proportions & 0.07 & 0.17 & 0.24 & \\
\hline Comparisons & q & $\mathrm{q}_{\text {critical }}$ & & \\
\hline $\mathrm{T} \times \mathrm{S}$ & 4.559 & 3.682 & & $\mathrm{~S}>\mathrm{T}$ \\
\hline $\mathrm{T} \times \mathrm{C}$ & 5.583 & 3.682 & & $\mathrm{C}>\mathrm{T}$ \\
\hline $\mathrm{C} \times \mathrm{S}$ & 1.705 & 3.682 & & $\mathrm{C}=\mathrm{S}$ \\
\hline \multicolumn{5}{|l|}{ Males } \\
\hline Proportions & 0.08 & 0.08 & 0.16 & \\
\hline Comparisons & q & $\mathrm{q}_{\text {critical }}$ & & \\
\hline $\mathrm{C} \times \mathrm{T}$ & 4.26 & 3.682 & & $\mathrm{C}>\mathrm{T}$ \\
\hline $\mathrm{C} \times \mathrm{S}$ & 1.95 & 3.682 & & $\mathrm{C}=\mathrm{S}$ \\
\hline $\mathrm{S} \times \mathrm{T}$ & 4.95 & 3.682 & & $\mathrm{~S}>\mathrm{T}$ \\
\hline \multicolumn{5}{|l|}{ Total } \\
\hline Proportions & 0.15 & 0.32 & 0.33 & \\
\hline Comparisons & q & $\mathrm{q}_{\text {critical }}$ & & \\
\hline $\mathrm{C} \times \mathrm{T}$ & 4.26 & 3.682 & & $\mathrm{C}>\mathrm{T}$ \\
\hline $\mathrm{C} \times \mathrm{S}$ & 1.95 & 3.682 & & $\mathrm{C}=\mathrm{S}$ \\
\hline $\mathrm{S} \times \mathrm{T}$ & 4.95 & 3.682 & & $\mathrm{~S}>\mathrm{T}$ \\
\hline
\end{tabular}

total $48 \mathrm{~h}$ the comparison showed significant difference among groups $\left(\chi^{2}=9.603, \mathrm{P}=0.008\right.$ and $\chi^{2}=18.412, \mathrm{P}=$ 0.0009 , respectively), while, for males, significant differences were obtained only for total $48 \mathrm{~h}\left(\chi^{2}=11.498, \mathrm{P}\right.$ $=0.00492$ ). For females plus males the differences among groups were significant in the two evaluations (for second $24 \mathrm{~h}: \chi^{2}=12.009, \mathrm{P}=0.004$ and for total 48 $\mathrm{h}\left(\chi^{2}=40.5689, \mathrm{P}=0.00001\right)$. Pairwise comparisons of groups showed that for females at the second $24 \mathrm{~h}$ and total $48 \mathrm{~h}$ the mortality of $\mathrm{S}$ flies was greater than that of
$\mathrm{T}$ and $\mathrm{C}$, which did not differ from each other (thus, $\mathrm{S}>\mathrm{T}$ $=\mathrm{C}$ ). At the second $24 \mathrm{~h}$, q values were $=3.749$ for $\mathrm{S} \times \mathrm{C}$, 3.401 for $\mathrm{S} \times \mathrm{T}$ and 0.349 for $\mathrm{T} \times \mathrm{C}$. For males, in the only significant counting (total $48 \mathrm{~h}$ ), pairwise comparesons also showed the sequence $\mathrm{S}>\mathrm{T}=\mathrm{C}$ (q values, in $\mathrm{S}$ $\times \mathrm{C}=4.174$, in $\mathrm{S} \times \mathrm{T}=3.937$ and in $\mathrm{T} \times \mathrm{C}=0.237)$.

Pairwise comparisons of the mortality degree for females + males also showed the sequence $\mathrm{S}>\mathrm{T}=\mathrm{C}$, in the three periods of analysis (for mortality rate at the first $24 \mathrm{~h}$, q values for $\mathrm{S} \times \mathrm{T}=4.559$, for $\mathrm{S} \times \mathrm{T}=4.174$ and for $\mathrm{T} \times \mathrm{C}=0.385$; at the second $24 \mathrm{~h}$, q values for $\mathrm{S} \times \mathrm{T}=$ 4.193, for $\mathrm{S} \times \mathrm{C}=3.987$, and for $\mathrm{T} \times \mathrm{C}=0.206$; and in the total $48 \mathrm{~h}, \mathrm{q}$ for $\mathrm{S} \times \mathrm{T}$, for $\mathrm{S} \times \mathrm{C}=6.275$, and for $\mathrm{C} \times$ $\mathrm{T}=0.000$. In every sex comparison critical $\mathrm{q}=3.377$. Thus, for all mortality comparisons $\mathrm{S}>\mathrm{T}=\mathrm{C}$.

\section{DISCUSSION}

A sublethal dose of the insecticide imidacloprid $(0.5$ $\mu \mathrm{g} / \mathrm{mL}$ culture medium) administered to Drosophila melanogaster affected the traits productivity, duration of the emergence period, viability of adults, longevity, viability during the development from egg to adults, and oviposition. Except oviposition that was affected in a different way, all the traits had their values reduced, revealing the toxicity of imidacloprid on Drosophila biology. These traits are among the ones that in the literature have been named life history traits because they are shaped by natural selection in the organism's lifetime, resulting in a variety of strategies for survival and reproduction $[19,20]$. Harmful effects on the life history traits such as these due to the insecticide imidacloprid (that is intensively used and thus practically continuously present in the environment) can put in risk these strategies and consequently the survival of the populations.

Relative to the productivity, 12 of the 15 generations showed lower numbers of progeny in the treated experiments $(\mathrm{T})$, although only in four generations the differences between control (C) and T were significant. Considering the 15 generations, the mean decrease of the males plus females in $\mathrm{T}$ was about $25 \%$ in relation to $\mathrm{C}$. However, the proportion of males and females produced in both $\mathrm{C}$ and $\mathrm{T}$ did not differ, suggesting equivalence of susceptibility of sexes to the insecticide in this trait. 
Table 8. Mortality (number and percentage) of females and males during $48 \mathrm{~h}$ to $10 \mu \mathrm{g} / \mathrm{ml}$ imidacloprid, computed in the first and the second $24 \mathrm{~h}$ and in the total $48 \mathrm{~h}$. Ninety males and ninety females were used for tests in control (C) and imidacloprid treated (T) groups, taken in the F15 generation, and also from the stocks which originated the experiments (S).

\begin{tabular}{ccccccc}
\hline & \multicolumn{3}{c}{ Females } & & \multicolumn{2}{c}{ Males } \\
\hline Group & $1^{\text {st }} 24 \mathrm{~h}$ & $2^{\text {nd }} 24 \mathrm{~h}$ & Total & $1^{\text {st }} 24 \mathrm{~h}$ & $2^{\text {nd }} 24 \mathrm{~h}$ & Total \\
$\mathrm{C}$ & $3(3.4 \%)$ & $8(8.9 \%)$ & $11(12.2 \%)$ & $3(3.4 \%)$ & $20(22.3 \%)$ & $23(25.56 \%)$ \\
$\mathrm{T}$ & $1(1.2 \%)$ & $9(10.0 \%)$ & $10(11.1 \%)$ & $6(6.7 \%)$ & $18(20.0 \%)$ & $24(26.7 \%)$ \\
$\mathrm{S}$ & $9(10.0 \%)$ & $21(23.4 \%)$ & $30(33.3 \%)$ & $13(14.4 \%)$ & $29(32.2 \%)$ & $42(46.7 \%)$ \\
\hline
\end{tabular}

The duration of the emergence period was also analyzed in every generation. In the light of the numbers, the mean emergence period of $\mathrm{C}$ flies was greater than that of $\mathrm{T}$, in nine of the 15 generations, although significant results were observed only in two of them. Taking into account all the generations, we observed for $\mathrm{T}$ a mean emergence period 2.13 days (15.5\%) shorter than that for $\mathrm{C}$, a difference that may not be neglected considering the mean value of 13.6 days for the duration of emergence in the control experiments. The correlation between the number of progeny and the emergence time duration also opened a new problem to be studied: is the decrease of emergence days due to a greater mortality of the larvae with longer developmental time and consequently with longer exposure to the insecticide?

The longevity (or lifespan) of D. melanogaster, in laboratory, is known since long ago as being about eight weeks. The influence of the genetic background and the environmental variation in their expression have also been demonstrated in laboratory tests as well by the significant variation in longevity observed within and among natural populations [21]. Our measures of longevity in C experiments showed values included in the known limits, while the treated flies showed mean longevity decrease of about four and eight days for females and males, respectively, showing that, for longevity, imidacloprid was more toxic for males than for females.

The viability egg-adult of the imidacloprid treated flies differed significantly between $\mathrm{T}$ and $\mathrm{C}$ experiments, with $\mathrm{T}$ producing lower percentage of adults than $\mathrm{C}$ and $\mathrm{S}$, which did not differ from each other. In the study of this and also the traits oviposition and tolerance, comparisons of $\mathrm{C}$ and $\mathrm{T}$ flies with flies from the stock (that had been normally maintained in the laboratory during the time of the study) were performed in order to detect possible effects of using the 15 first couples for producing the consecutive generations. Thus, for viability egg to adult this effect apparently does not occur. The lower viability of the treated flies during development may be an important factor to explain the lower productivity observed under the imidacloprid effect. The harmful effect on the viability egg-adult of Drosophila has also been described in experiments with other insecticides [22].
Oviposition was affected by imidacloprid in a different way. It provoked a decrease of the pre-oviposition time. At $22 \mathrm{~h}$, T flies had laid 55\% of the total number of eggs counted in the complete period of analysis $(44 \mathrm{~h})$, a percentage significantly higher than the $15 \%$ laid by $\mathrm{C}$ flies in the same period. Since in S flies the egg-laying time did not differ significantly from $\mathrm{C}$, the anticipation of oviposition in that period apparently was not influenced by the method of preparing the consecutive generations. However, at $44 \mathrm{~h}$, while $\mathrm{S}$ remained in a slow pace, $\mathrm{T}$ and $\mathrm{C}$ oviposition rates equaled due to the significant increase of the egg number in C. Recently, [4] also reported a shortening of the pre-oviposition period in the mirid bug Apoligus lucorum treated with imidacloprid, but parallel to this shortening they observed an increase of the embryogenesis time that doesn't seem to occur in our study in Drosophila because we detected decrease in the duration of the emergence period of the treated flies. The meaning and the mechanism of these changes in oviposition remain to be understood.

The development of resistance to imidacloprid has been reported in many insect species, including field populations and laboratory selected strains (in honeybee, [9]; in the whitefly Bemisia tabaci $[23,24]$; in the brown planthoper Lugaparvata lugens [25] and in the potato beetle Leptinitarsa decemlineata [26]. In the present study, although we had not selected the flies for resistance with the usual method (selecting the more resistant flies in each generation to prepare the next), during 15 successive generations the parental adults and the larvae of the $\mathrm{T}$ experiments were fed exclusively with the culture medium containing imidacloprid. We expected that, if some tolerance had developed, the number of progeny would increase in $\mathrm{T}$ experiments over the generations. The smoothing technique applied to the productivity data revealed more clearly, in graph, a tendency for this increase. However, the increase occurred in $\mathrm{C}$ and $\mathrm{T}$ experiments, which allowed hypothesizing that the use of the first 15 emerged couples to prepare the consecutive generations was revealing an interaction between emergence speed and productivity. In situations like this, the characteristics that seem to be interdependent must be necessarily considered genetically correlated [27]. 
A similar idea resulted from the study of mortality of adult flies exposed to the imidacloprid, in which we compared flies from $\mathrm{C}$ and $\mathrm{T}$ experiments, and also flies from the stock (S). The mortality of flies from $\mathrm{S}$ was higher than that of $\mathrm{C}$ and $\mathrm{T}$, which, in turn, did not differ from each other. These results indicated that the tolerance in $\mathrm{C}$ and $\mathrm{T}$, as also observed in the productivity increase is, in some way, related with the selection for emergence speed. Previous studies on emergence time in Drosophila suggested that this trait can be correlated with fecundity [28] and with stress resistance [29] reinforcing the present hypothesis.

In summary, the present work showed harmful effects of the insecticide imidacloprid on Drosophila, affecting a set of important components of organisms' fitness. Beyond this focus on the biological danger due to the extensive presence of this neonicotinoid in the environment, the analysis of different biological traits allowed proposing a relationship of cause and effect among some of them (for example, the viability decrease during development from egg to adult and the productivity decrease, in the treated experiments). There are also other questions such as the possible shortening of the emergence period due to a preferential mortality of the larvae delayed in development and consequently exposed longer to the insecticide; another question is what the consequences of the pre-oviposition time decrease are-Are these eggs viable? Do they develop earlier?

Furthermore, the results suggested the interplay of the trait developmental speed of flies with other characteristics such as progeny number and development of tolerance. This aspect also deserves further studies, for Drosophila melanogaster is a very propitious model.

The clarifying of the mentioned questions will be important, considering, on one side, the need to increase the knowledge on the effects of imidacloprid considered currently the insecticide of prevalent use in the world, and, on the other, the still poor knowledge of the mechanisms underlying the adaptive traits.

\section{ACKNOWLEDGEMENTS}

Research supported by FAPESP (Scientific initiation fellowship, Thais de França Patarro).

\section{REFERENCES}

[1] Yamamoto, I. and Casida, J.E. (1999) Nicotinoid insecticides and the nicotinic acetylcholine receptor. Springer Verlag, Berlin.

[2] Bayer Crop Science (2013) Imidacloprid. http://www.bayergroupindia.com/imidacloprid.html

[3] Bao, H., Liu, S., Gu, J., Wang, X., Liang X. and Liu, Z. (2009) Sublethal effects of four insecticides on the reproduction and wing formation of brown planthopper,
Nilaparvata lugens. Pest Management Science, 65, 170174. http://dx.doi.org/10.1002/ps.1664

[4] Tan, Y., Biondi, A., Desneux, N. and Gao, X. (2012) Assessment of physiological sublethal effects of imidacloprid on the mirid bug Apolygus lucorum (Meyer-Dür). Ecotoxicology, 21, 1989-1997.

http://dx.doi.org/10.1007/s10646-012-0933-0

[5] Blacquière, T., Smagghe, G., Van Gestel, C.A.M. and Mommaerts, V. (2012) Neonicotinoids in bees: A review on concentrations, side-effects and risk assessment. Ecotoxicology, 21, 973-992. http://dx.doi.org/10.1007/s10646-012-0863-x

[6] Bortolotti, L., Montanari, R., Marcelino, J., Medrzycki, P., Maini, S. and Porrini, C., (2003) Effects of sub-lethal imidacloprid doses on the homing rate and foraging activity of honey bees. Bulletin of Insectology, 56, 63-67.

[7] Henry, M., Béguin, M., Requier, F., Rollin, O., Odoux, J., Aupinel, P., Aptel, J., Tchamitchian, S. and Decourtye, A. (2012) A Common Pesticide Decreases Foraging Success and Survival in Honey Bees. Science, 336, 348-350. http://dx.doi.org/10.1126/science.1215039

[8] Tapparo, A., Marton, D., Giorio, C., Zanella, A., Solda, L., Marzaro, M., Vivan, L. and Girolami,V. (2012) Assessment of the environmental exposure of honeybees to particulate matter containing neonicotinoid insecticides coming from corn coated seeds. Environmental Science \& Technology, 46, 2592-2599. http://dx.doi.org/10.1021/es2035152

[9] Johnson, R.M., Ellis, M.D., Mullin, C.A. and Frazier, M., 2010. Pesticides and honey bee toxicity-USA. Apidologie, 41, 312-331. http://dx.doi.org/10.1051/apido/2010018

[10] Tomizawa, M. and Casida, J.E. (2003) Selective toxicity of neonicotinoids attributable to specificity of insect and mammalian nicotinic receptors. Annual Review of Entomology, 48, 339-364. http://dx.doi.org/10.1146/annurev.ento.48.091801.112731

[11] Jeschke, P. and Nauen, R. (2008) Neonicotinoids-From zero to hero in insecticide chemistry. Pest Management Science, 64, 1084-1098. http://dx.doi.org/10.1002/ps.1631

[12] Magalhães, L.C., Hunt, T.E. and Siegfried, B.D. (2008) Development of methods to evaluate susceptibility of soybean aphid to imidacloprid and thiamethoxam at lethal and sublethal concentrations. Entomologia Experimentalis et Applicata, 128, 330-336. http://dx.doi.org/10.1111/j.1570-7458.2008.00718.x

[13] Sarkar, M.A., Biswas, P.K., Roy, S., Kole, R.K. and Chowdhury, A. (1999) Effect of $\mathrm{pH}$ and type of formulation on the persistence of lmidacloprid in water. Bulletin of Environmental Contamination and Toxicology, 63, 604-609. http://dx.doi.org/10.1007/s001289901023

[14] Anatra-Cordone, M. and Durkin, P. (2005) Human Health and Ecological Risk Assessment. Final Report, USDA/ Forest Service/ Forest Health Protection, New York.

[15] Niwa, R. and Niwa, Y. S. (2011) The fruit fly Drosophila melanogaster as a model system to study cholesterol metabolism and homeostasis. Cholesterol, 2011, 1-6. http://dx.doi.org/10.1155/2011/176802 
[16] Wolf, M.J. and Rockman, H.A. (2008) Drosophila melanogaster as a model system for the genetics of postnatal cardiac function. Drug Discovery Today, 5, 117123.

[17] Zar, J.H. (1999) Biostatistical Analysis. Prentice Hall, New Jersey.

[18] Moore, D.A. (2004) Estatística Básica e Sua Prática. Livros Técnicos e Científicos S.A., Brasil.

[19] Stearns, S.C. (1977) The evolution of life history traits: a critique of the theory and a review of the data. Annual Review of Ecology, Evolution, and Systematics, 8, 145171.

http://dx.doi.org/10.1146/annurev.es.08.110177.001045

[20] Fabian, D. and Flatt, T. (2012) Life History Evolution. Nature Education Knowledge Project. 3, 24. http://www.nature.com/scitable/knowledge/library/life-his tory-evolution-68245673

[21] Paaby, A.B. and Schmidt, P.S. (2009) Dissecting the genetics of longevity in Drosophila melanogaster. Fly, 3, 29-38. http://dx.doi.org/10.4161/fly.3.1.7771

[22] Karataş, A., Bahçeci, Z. and Başpinar, E. (2011) The effect of diazinon on egg fertility and development in Drosophila melanogaster. Turkish Journal of Biology, 35, 95-101.

[23] Sethi, A., Bons, M.S. and Dilawari, V.K. (2008) Realized heritability and genetic analysis of insecticide resistance in whitefly, Bemisia tabaci (Genn.). Journal of Entomology, 5, 1-9. http://dx.doi.org/10.3923/je.2008.1.9

[24] Liu, Z. and Han, Z. (2006) Fitness costs of laboratory- selected imidacloprid resistance in the brown planthopper, Nilaparvata lugens Stål. Pest Management Science, 62, 279-282. http://dx.doi.org/10.1002/ps.1169

[25] Wen, Y., Liu, Z., Bao, H. and Han, Z. (2009) Imidacloprid resistance and its mechanisms in field populations of brown planthopper, Nilaparvata lugens Stål in China. Pesticide Biochemistry and Physiology, 94, 36-42. http://dx.doi.org/10.1016/j.pestbp.2009.02.009

[26] Alyokhin, A., Dively, G., Patterson, M., Castaldo, C., Rogers, D., Mahoney, M. and Wollam J. (2006) Resistance and cross-resistance to imidacloprid and thiamethoxam in the Colorado potato beetle Leptinotarsa Decemlineata. Pest Management Science, 63, 32-41. http://dx.doi.org/10.1002/ps.1305

[27] Fuller, R.C., Baer, C.F. and Travis, J. (2005) How and When Selection Experiments Might Actually Be Useful. Integrative and Comparative Biology, 45, 391-404. http://dx.doi.org/10.1093/icb/45.3.391

[28] Nunney, L. (1996) The response to selection for fast larval development in Drosophila melanogaster and its effect on adult weight: An example of a fitness trade-off. Evolution, 50, 1193-1204. http://dx.doi.org/10.2307/2410660

[29] Sørensen, J.G. and Loeschcke, V. (2004) Effects of relative emergence time on heat stress resistance traits, longevity and hsp70 expression level in Drosophila melanogaster. Journal of Thermal Biology, 29, 195-203. http://dx.doi.org/10.1016/i.jtherbio.2004.02.004 